\title{
SENDING A Bit MORE COIN HOME? AN ANALYSIS OF RETAIL USER PROTECTION IN BITCOIN REMITTANCE MARKETS
}

\author{
Jared Cotton*
}

\begin{abstract}
This article examines the use of Bitcoin in money remittance markets as a specific illustration of wider emerging regulatory issues relating to the use of cryptocurrencies. While there are many conceivable benefits of using Bitcoin for remittances, there are also many risks for users of these remittance services. This article adopts a user perspective to look at what the major concerns are and what existing protections may be available to persons using cryptocurrencies under New Zealand law through the example of using Bitcoin for remittance purposes. The article then summarises approaches taken by other jurisdictions before suggesting a specific regulatory approach to cryptocurrencies that New Zealand should consider adopting.
\end{abstract}

\section{INTRODUCTION}

Throughout history, currency has existed in many forms. ${ }^{1}$ At its heart, currency is a social construct: what people are collectively willing to use as currency becomes currency. ${ }^{2}$ Currency can be anything with the facility to "store value, measure value and facilitate transactions". ${ }^{3}$ Historically, for example, gold, silver and conch shells have all been used as currency. ${ }^{4}$ The latest form of currency

* Submitted as part of the LLB (Hons) programme at Victoria University of Wellington. I am sincerely grateful for the guidance and feedback from my supervisor, Victoria Stace. This article was written with the information available at February 2018. I acknowledge that the fast-changing nature of cryptocurrency may make elements of this article no longer current at the time of publication.

1 "Digital Currencies: A new specie" The Economist (online ed, London, 13 April 2013).

2 Rhys Bollen "The Legal Status of Online Currencies: Are Bitcoins the Future?" (paper presented to Financial Institutions, Regulation \& Corporate Governance Conference, Melbourne, 2016) at 1.

3 Bollen, above $\mathrm{n} 2$, at 1 .

4 SJ Butlin "Foundations of the Australian Monetary System 1788-1851" (2002) University of Sydney Library $<$ http://adc.library.usyd.edu.au>. 
are cryptocurrencies, "computerised money [which] exists only as strings of digital code". 5 Cryptocurrencies present unique regulatory challenges relating to financial markets regulation, user protection, and anti-money laundering and counter-terrorist financing. Bitcoin is one such cryptocurrency which has recently jumped into the spotlight due to the disruptive potential of its underlying blockchain technology. ${ }^{6}$ Bitcoin is a complex and technical financial innovation, yet is accessible to users through free and open-source software. ${ }^{7}$ Many intermediary businesses have emerged to help facilitate users' access to the Bitcoin network. ${ }^{8}$

This article considers the emerging regulatory issues presented by cryptocurrencies through an examination of one developing use of Bitcoin: how Bitcoin can disrupt the money remittance sector through its usage of blockchain technology. The focus of this article is the current regulatory treatment of Bitcoin in relation to retail user protection. It is not a comprehensive analysis of all the regulatory implications of cryptocurrencies or blockchain technology. However, the same legal analysis could also apply to many other aspects of cryptocurrency services, such as cryptocurrency exchanges. The context for this discussion is through the example of unsophisticated users of Bitcoin for remittances and whether they are sufficiently protected from the risks Bitcoin presents. Part II outlines the state of the traditional money remittance market in New Zealand. Part III discusses how Bitcoin works and the importance of its underlying blockchain technology. Part IV looks at how Bitcoin has the potential to disrupt remittance markets and discusses the key risks and practical difficulties which exist for Bitcoin remittance users. Part V offers an analysis of how Bitcoin could fit within the current regulatory framework and provides a snapshot of how this compares with other jurisdictions. Part VI presents recommendations for New Zealand to adopt: specifically, cryptocurrency services should be made a "prescribed intermediary service". Finally, the article concludes that while existing regulatory structures may provide cryptocurrency service users with modest protection, Bitcoin remittances will remain a problematic option for unsophisticated retail users unless regulators commit to promoting user protections and fostering growth in the cryptocurrency industry.

\section{THE MONEY REMITTANCE MARKET IN NEW ZEALAND}

Money remittance providers supply international money transfer services. The most common users are migrants who want to send small sums of money home to their families. ${ }^{9}$ Often, the money

5 The Economist, above n 1.

6 Louise Parsons "Bitcoin - sending money home" (paper presented to Banking \& Financial Services Law Association Conference, Queenstown, 2016) at 12.

7 European Central Bank Virtual Currency Schemes (October 2012) at 27.

8 Parsons, above $\mathrm{n}$ 6, at 16

9 World Bank Group Migration and Remittances Factbook 2016 (3rd ed, Washington, 15 December 2015) at vii. 
is sent to developing countries. ${ }^{10}$ In 2015 , the amount of private remittances sent to developing countries was more than three times the amount of official aid money provided to developing countries, which signifies the importance of private money flows for local economies. ${ }^{11}$ Remittance cost data is collected assuming that $\$ 200$ is being remitted. ${ }^{12}$ The cost of sending remittances is highest for those sent to Africa and the Pacific Islands. ${ }^{13}$ For example, it costs approximately 20 per cent to send \$200 from New Zealand to Papua New Guinea. ${ }^{14}$ This is more than double the worldwide average for remittance costs of eight per cent, and substantially higher than the three per cent Sustainable Development Goals target set by the United Nations. ${ }^{15}$ According to World Bank data, New Zealand remitted USD 2.4 billion worldwide in $2015 .{ }^{16}$ In 2016, there were 1.5 million immigrants living in New Zealand. ${ }^{17}$ This was almost a third of the population. ${ }^{18}$ The top countries these immigrants originally came from includes: Fiji, Samoa and Tonga. ${ }^{19}$

Migrants send money home for a variety of reasons, such as: supporting household incomes, giving gifts and urgent matters such as funerals or natural disasters. ${ }^{20}$ Poverty has been a rising and substantial problem for many Pacific Island countries. Remittances play a key humanitarian role in providing stable income in what can be an unstable financial environment. ${ }^{21}$ Aside from the

10 Worldwide remittances in 2015 were estimated at over USD 601 billion, of which USD 441 billion was sent to developing countries: World Bank Group, above $\mathrm{n} 9$, at xii.

11 At xii.

12 See World Bank Group "Methodology" Remittance Prices Worldwide < http://remittanceprices.world bank.org>.

13 World Bank Group, above n 9, at xii.

14 SendMoneyPacific "New Zealand to Papua New Guinea" (20 July 2017) <www.sendmoneypacific.org>.

15 World Bank Group, above n 9, at xii; and Transforming our world: the 2030 Agenda for Sustainable Development GA Res 70/1, A/Res/70/1 (2015).

16 World Bank Group "Migration and Remittances Data: Bilateral Remittance Matrix 2015" (24 September 2015) <www.worldbank.org>.

17 World Bank Group, above n 9, at 195; and Ministry of Business, Innovation, and Employment Migration Trends 2015/2016 (November 2016) at 4.

18 Total New Zealand population for 2016 was 4,692,700: World Bank Group "Population, total" The World Bank Data <https://data.worldbank.org>.

19 World Bank Group, above n 9, at 195

20 Deloitte Review of the Money Remittance Market in New Zealand: A report on the problems affecting services between New Zealand and the Pacific (Treasury, August 2016) at 33. See also Dilip Ratha, Head of KNOMAD at The World Bank "The hidden force in global economics: sending money home" (TEDGlobal, Rio de Janeiro, Brazil, 9 October 2014).

21 See Monica Costa and Rhonda Sharp The Pacific Island Countries Fiji, Papua New Guinea (PNG), Samoa, Solomon Islands, Vanuatu and Tuvalu (University of South Australia, 2011). 
significance for individual recipients, there is a broader social importance for remittances, with inflows having a large effect on the recipient country's economy. Some Pacific Island countries benefit greatly from remittances sent from New Zealand. For example, Tonga receives remittances equal to almost 30 per cent of its GDP. ${ }^{22}$ Almost 40 per cent of all remittances sent to Tonga come from New Zealand. ${ }^{23}$ Remittances have grown consistently in recent years, showing resilience to economic developments during periods of market volatility. ${ }^{24}$ This helps to stabilise fluctuations in local economies caused when other capital flows weaken. ${ }^{25}$ Thus, there is both an individual and a broader social benefit for reducing the cost of remittances.

\section{A Traditional Money Remittance Options}

There are numerous traditional ways of remitting funds, such as: physical currency transfers, banks, Money Transfer Operators (MTOs), informal International Fund Transfer Operators (IFTOs) and various electronic transfer systems.

(a) Physical currency transfers

This includes sending cash through the post or with people who travel between countries. ${ }^{26}$

(b) Banks

This requires the use of financial intermediaries and includes an electronic transfer from a New Zealand bank to the foreign bank account of the recipient. While possibly the most reliable method, it is also generally the most expensive. ${ }^{27}$ Special cards have been created which allow money to be loaded into an account in New Zealand and withdrawn from the account in a different country. However, fees are charged both for converting the currency and in the exchange rate margin, meaning it can still cost large amounts to remit funds. ${ }^{28}$

22 World Bank Group, above n 9, at 13.

23 See World Bank Group, above n 16.

24 World Bank Group "Migration and Remittances Data: Annual Remittances Data Inflows" (October 2017) <www.worldbank.org>.

25 Parsons, above n 6, at 5.

26 See Deloitte, above n 20, at 10.

27 See at 10 .

28 Westpac "Credit Cards: Prepaid cards" <www.westpac.co.nz>; and SendMoneyPacific "Compare International Money Transfer Costs" <www.sendmoneypacific.org>. 
(c) MTO

This is a specialist international money transfer institution which provides money remittance services, such as Western Union. ${ }^{29}$

(d) Informal IFTOs

These systems (often referred to as hawala remittances) rely on a trust network to transfer funds. ${ }^{30}$ In practice, however, there is no actual fund transfer or movement of money across borders. Instead, small businesses act as cash-in and cash-out agents, later settling debts between themselves in bulk for a margin profit. ${ }^{31}$

(e) Electronic transfer systems

This includes transferring money between Paypal accounts and mobile phone remittance services where credit is transferred from one mobile to another through an SMS message. ${ }^{32}$

\section{B Current Issues with Traditional Money Remittances}

Although remittances play a key role in supporting both individuals and society in developing nations, there are many issues with current systems for remitting money. These can be categorised as: risk, trust and cost. The least risky way to remit small sums of money is to deliver cash physically. However, for most, this is impractical on a regular basis. Users may struggle to find a trustworthy individual to transport cash from one country to another on their behalf. Additionally, users cannot always trust postal systems to deliver cash. These options are especially unfeasible where funds are required to be transferred urgently. Thus, trust and speed are the biggest disadvantages of a private physical currency transfer system. ${ }^{33}$ To get around this issue, many users turn to other options such as MTOs, prepaid cards or pre-paid online accounts. However, here the sender assumes the risk that the counterparty (the service provider) fails and there is a loss of all or some funds. To mitigate this risk, users may choose to use a reputable bank or MTO to increase their trust in the remittance arriving safely. However, there is an inverse relationship between risk and cost. While well-known banks and MTOs are more reliable, they are typically more expensive. ${ }^{34}$ This shows the ideal remittance transfer

29 See Deloitte, above n 20, at 10.

30 Marie Chêne "Hawala Remittance System and Money Laundering" (23 May 2008) U4 Anti-Corruption Resource Centre <http://www.u4.no>.

31 See Deloitte, above n 20, at 10.

32 See at 10 .

33 Parsons, above n 6.

34 See Deloitte, above n 20, at 10. 
would be a direct person to person electronic remittance through a system users can trust without a high cost. Some have claimed Bitcoin has the potential to provide this facility.

\section{WHAT IS BITCOIN?}

Bitcoin is "[a] purely peer-to-peer version of electronic cash [that allows] online payments to be sent directly from one party to another without going through a financial institution. ${ }^{35}$ It is a digital currency that is "denominated in its own units of account". ${ }^{36}$ Its exchange rate is determined by market forces, just like United States dollars. ${ }^{37}$ Bitcoin operates using blockchain technology. Blockchain is the system which facilitates and records the payment of Bitcoin from one party to another, though blockchain technology is not exclusive to Bitcoin. ${ }^{38}$ A blockchain is a distributed ledger which facilitates the transmission of transactions to all nodes on a network. ${ }^{39}$ A distributed ledger is simply a database that spans across numerous sites or countries. ${ }^{40}$ Bitcoin's blockchain uses cryptography by giving users a public and private key to encrypt and decrypt transactions. ${ }^{41}$ While the public key ensures all transactions are broadcast publicly, only the holder of Bitcoin can initiate a transaction using their private key. ${ }^{42}$ Thus, each users Bitcoins are protected from theft as long as they keep their private key safe.

When using the blockchain, parties transact with each other by notifying every participant on the network the transaction is taking place. ${ }^{43}$ Through a process known as mining, transactions are verified and bundled into a block. Miners are Bitcoin users who choose to volunteer their computer's processing power to the blockchain to iteratively solve complex algorithms which are required to verify transactions and create new transaction blocks. ${ }^{44}$ Anyone may do this, but it requires substantial

35 Satoshi Nakamoto "Bitcoin: A Peer-to-Peer Electronic Cash System" (2008) Bitcoin <https://bitcoin.org> at 1.

36 Bollen, above $\mathrm{n} 2$, at 3 .

37 European Central Bank, above n 7, at 21.

38 For examples of other uses see Paul Brody and others "Blockchain reaction: tech companies plan for critical mass" (EY, 2016).

39 A node is an individual network participant: Sigrid Seibold and George Samman "Consensus: Immutable agreement for the Internet of value" (KPMG, 2016).

40 United Kingdom Government Chief Scientific Adviser Distributed Ledger Technology: beyond block chain (GS/16/1, December 2015) at 17

41 Bollen, above n 2, at 6.

42 See Nakamoto, above n 35 .

43 Nakamoto, above n 35.

44 See Nicholas Plassaras "Regulating Digital Currencies: Bringing Bitcoin Within the Reach of the IMF" (2013) 14 Chicago Journal of International Law 377 at 386. 
central processing unit power. ${ }^{45}$ Miners are rewarded for this in two ways: first, they are rewarded with a new amount of Bitcoin which is created by the blockchain when each new block is "mined"; 46 second, miners are paid a small fee as an incentive by users whose transactions are being mined. Generally speaking, the larger fee a user chooses to attach to the transaction, the faster it will be mined. ${ }^{47}$ Only the miner who successfully validates the block and adds it to the blockchain is rewarded. ${ }^{48}$

The new block is added to the blockchain by being transmitted to all users on the Bitcoin network to validate and keep a record. ${ }^{49}$ All participants validate a block automatically when it is transmitted to them. The type of algorithms used are hard to solve, but easily verified by other participants. ${ }^{50} \mathrm{As}$ all participants verify and record all transaction blocks, there is no need to check with a central authority. The lack of central authority means there is no controlling body which issues Bitcoin into circulation. ${ }^{51}$ This separates Bitcoin from fiat currencies. Instead, there is a predetermined finite number of Bitcoin which can be mined to enter circulation. ${ }^{52}$ The number of Bitcoin mined for each new block of the blockchain is halved every 210,000 blocks. At the current reward rate the total number of Bitcoin which will enter circulation is 21 million. Due to the collective nature of the record, in conjunction with the proof-of-work algorithm system which Bitcoin's blockchain uses for consensus on what the correct record is, it is practically impossible to counterfeit or make changes to the blockchain. As such, Bitcoin's blockchain becomes practically immutable. ${ }^{53}$

\section{REMITTANCES USING BITCOIN}

\section{A The Business Case}

Remittances using Bitcoin, referred to as "rebittances", allow a transfer of value that can be effected quickly and only requires users to have network access and a smartphone to transact anywhere in the world. ${ }^{54}$ As statistics indicate that almost all remittance users have a smartphone, this

45 At 386

46 See Nakamoto, above n 35.

47 Edward Murphy, Maureen Murphy and Michael Seitzinger Bitcoin: Questions, Answers, and Analysis of Legal Issues (Congressional Research Service, 13 October 2015) at 2.

48 See Nakamoto, above n 35.

49 Trevor Kiviat "Beyond Bitcoin: Issues in Regulating Blockchain Transactions" (2015) 65 Duke LJ 569.

50 Seibold and Samman, above n 39, at 12.

51 "Virtual Currencies: Mining digital gold" The Economist (online ed, London, 13 April 2013).

52 European Central Bank, above n 7, at 21.

53 See Nakamoto, above n 35.

54 Parsons, above n 6, at 19. 
could entirely transform the remittance market. ${ }^{55}$ As some in the industry have commented, the "reason Bitcoin will disrupt the remittance industry is because anyone can send $\$ 20$ or even less to anyone ... get it within 8 hours, even without a bank account, and still only pay $1 \%-4 \%$ [in fees] at the most." 56 Currently, rebittances can be sent either directly or through the use of a rebittance provider.

In a direct transaction, a user sends Bitcoin from their virtual wallet to the intended recipient's wallet. The users can either operate their own nodes on the blockchain or, due to the power intensive nature of maintaining a node, may operate through a third-party wallet service such as BitPay. ${ }^{57} \mathrm{By}$ using a third-party wallet service, users only require a smartphone with Internet access to transact using Bitcoin. This is the ideal remittance method as it is a direct electronic transfer that requires no trusted intermediary to deliver the remittance. And the only fee incurred is that which the sender attaches to the transaction to have it mined faster. ${ }^{58}$ However, this kind of direct transfer assumes: (a) the sender already holds an amount of Bitcoin; and (b) the recipient can spend Bitcoin without conversion into fiat currency. Currently, this is not generally possible. However, if Bitcoin became more prevalent, this could be a possibility in the future.

Instead, and currently, users would generally need to exchange fiat currency for Bitcoin (and vice versa for recipients) through a Bitcoin exchange or use a rebittance provider. Globally, there are many rebittance providers and the number continues to grow. ${ }^{59}$ Use of a rebittance provider allows users to send fiat currency to a recipient who receives a payout in fiat currency. The rebittance provider uses blockchain technology to transfer funds and subsequently convert Bitcoin into the recipient's fiat currency for them to withdraw through a bank account, mobile phone or teller. ${ }^{60}$

For example, one of the best-known providers, Abra, allows users to sign up using their smartphone "app". 61 The user creates a non-custodial Bitcoin wallet by providing basic information, such as a name and email address. This means the app creates a Bitcoin wallet that presents the value of the Bitcoin in a currency of the users choosing which only the user has access to. Internationally, a user can add or withdraw Bitcoin to or from their Abra wallet through a bank transfer with any major bank, physically through Abra tellers, by buying online, or by transferring Bitcoin they already own

55 At 3 .

56 SaveOnSend "Before you Transfer Money" (25 July 2016) <www.saveonsend.com> as cited in Parsons, above $\mathrm{n} 6$.

57 Bitpay "Get started with blockchain payments" <https://bitpay.com>.

58 See Murphy, Murphy and Seitzinger, above n 47.

59 Parsons, above $\mathrm{n} 6$, at 16

60 Abra "Sending and receiving cash" <https://abra.zendesk.com>.

61 Abra "Buy Bitcoin with Abra" < www.abra.com>. 
from another wallet. In New Zealand, adding or withdrawing Bitcoin through a bank transfer is not currently offered by Abra and users must choose one of the other options for adding funds to their Abra wallet. ${ }^{62}$ Once users have Bitcoin in their wallet they can transfer it over the blockchain in what amounts to a smartphone-to-smartphone transaction, regardless of location, mobile operator or currency with no fees charged by Abra. ${ }^{63}$

\section{$B$ The Reality}

The International Monetary Fund (IMF) suggests blockchain based settlement systems are faster than conventional systems. ${ }^{64}$ This is one advantage rebittance providers can offer users. However, in practice, this requires the use of other third parties to exchange Bitcoin into fiat currency. This adds further procedural steps for the remittance to be complete. ${ }^{65}$ A lack of Bitcoin exchanges in small economies such as the Pacific Islands could mean more time will elapse before a recipient receives cash they can use, compared to using systems which are already established.

The problem of speed is exacerbated as Bitcoin increases in scale. ${ }^{66}$ Currently, blocks on the Bitcoin blockchain are limited to one megabyte in file size. As a transaction is approximately 500 bytes on average, the average block contains around 2000 transactions. ${ }^{67}$ As blocks can only be mined every 10 minutes, this limits the number of transactions able to be processed, leading to longer processing times. However, steps have already been taken to make Bitcoin more scalable by allowing more transactions to be included in each block. ${ }^{68}$ Thus, similar steps could be taken in the future to allow Bitcoin to function more efficiently as it grows. However, Bitcoin's core community appear reluctant to change rules regarding how transactions are processed. ${ }^{69}$

The IMF also indicates that Bitcoin can reduce the cost of remittances because of blockchain technology. ${ }^{70}$ Goldman Sachs has estimated the cost of a rebittance to be approximately one per

62 Abra "Where is Abra Available?" <www.abra.com>.

63 Abra "Fees" <https://abra.zendesk.com>.

64 Dong He and others Virtual Currencies and Beyond: Initial Considerations (International Monetary Fund, January 2016).

65 Parsons, above n 6.

66 Simon Barber and others "Bitter to Better - How to Make Bitcoin a Better Currency" (2012) 7397 Lecture Notes in Computer Science 399.

67 Blockchain "Average Number of Transactions Per Block" <https://blockchain.info>.

68 Joseph Young "How Segwit is Bitcoin's Blocksize Solution \& What Happens After" (19 March 2017) Cryptocoin News <www.cryptocoinnews.com>.

69 David Dinkins "Collapse of Bitcoin's 'New York Agreement' Would Have Long Term Consequences" (16 September 2017) Coin Telegraph <www.cointelegraph.com>.

70 He and others, above n 64. 
cent. ${ }^{71}$ This is much lower than the current eight per cent average cost of remittances globally. ${ }^{72}$ Notably, remittance costs are influenced by many factors, such as the use of agents. ${ }^{73}$ Abra uses agents through its Abra tellers, for which it charges a 1.5 per cent fee to exchange Bitcoin and fiat currency. ${ }^{74}$ Even accounting for this, the total cost of a remittance through Abra would be four per cent. However, there has recently been a rise in the cost of transactions over the Bitcoin blockchain which is linked to the increased volume of Bitcoin transactions. As volume has increased, users have attached greater miner's fees to their transactions so as to have them processed faster. ${ }^{75}$ This recent increase in cost for transacting with Bitcoin has reduced the utility it can provide for use in remittances. It is unclear whether this increase in transaction costs is permanent. Other cryptocurrencies have emerged which do not suffer from the same transaction cost and scalability issues as Bitcoin. ${ }^{76}$ However, these other cryptocurrencies present many of the same risks to users as Bitcoin.

\section{The Risks for Users}

Bitcoin is a complex and technical financial innovation, yet is accessible to users through free and open-source software. This is a clear case of information asymmetry. Unsophisticated users may attempt to use Bitcoin without understanding the risks they are taking when transacting with it. This, coupled with the legal uncertainty and lack of close monitoring by regulators, creates a high-risk environment for users. ${ }^{77}$

One of the largest risks of using Bitcoin is price volatility, which is considerable when compared with fiat currencies. During January 2018, Bitcoin had an average daily change in value of five per cent and fell 25 per cent over the month. ${ }^{78}$ In comparison, the NZD/USD exchange rate had an average daily change of less than half a per cent and only changed 3.5 per cent throughout January. ${ }^{79}$ This volatility risk is present when fiat currency is exchanged into Bitcoin and vice versa. Additionally, Bitcoin has been exposed to flash crashes where Bitcoin's value rapidly depreciated

71 Goldman Sachs "All About Bitcoin" (11 March 2014) 21 Global Macro Research Top of Mind 1 at 8.

72 World Bank Group, above n 9, at xii.

73 Parsons, above n 6.

74 Abra, above n 63.

75 Jaime Redman "Rising Network Fees are Causing Changes within the Bitcoin Economy" (9 June 2017) Bitcoin <https://news.bitcoin.com>.

76 See for example Stellar <www.stellar.org>; and Ripple <www.ripple.com>.

77 European Central Bank, above n 7, at 27.

78 CoinDesk "Bitcoin Price Index" <www.coindesk.com>.

79 Reserve Bank of New Zealand "Exchange rates and TWI - B1 Daily (2014-current)" <www.rbnz.govt.nz>. 
large amounts. ${ }^{80}$ As current Bitcoin remittances require exchange between fiat currency and Bitcoin for practical purposes, the risk of potential exchange loss is hard to avoid. Until Bitcoin can be used directly and there is no need for exchange with fiat currency, Bitcoin remittances will carry significant exchange rate risk. This poses the question of whether the heightened risk requires a regulatory response. Due to the distributed nature of the blockchain, any attempts at product regulation are likely to be ineffective at controlling price. Instead, users of Bitcoin will best be protected if they are made aware, through disclosure of the exchange rate risk, and are able to make informed decisions when choosing to use Bitcoin for remittances.

Another risk which cannot be ignored is the immutable nature of the blockchain and the lack of central authority. For users, this means mistaken or fraudulent transactions cannot be halted or undone. ${ }^{81}$ If a user accidentally sends their Bitcoin to the wrong address or their private key is compromised, then there is no recourse for users to get their Bitcoin back. ${ }^{82}$ There have been instances of large Bitcoin exchanges and wallet providers suspending services and being liquidated due to hacking activities where thousands of Bitcoin (worth millions of USD) have been stolen. ${ }^{83}$ These have resulted from the security faults of exchanges, not the underlying blockchain technology. ${ }^{84}$ In these cases, users generally bore the loss. ${ }^{85}$ This raises regulatory concerns as to whether users need protection against naively using technology they do not understand and losing their money or being fraudulently taken advantage of. At the very least this issue requires disclosure obligations. Product regulation and ensuring avenues to recourse for users would allow for more robust user protection in relation to third-party failure. Currently the market is fragmented; there are many small players that are competing and no clear way for users to identify reliable rebittance providers they can trust. This risk is exacerbated through a lack of New Zealand based rebittance providers. Licensing requirements could be an effective mechanism for signaling reputable Bitcoin businesses to users.

The risks presented by information asymmetry, price volatility, irreversibility of transactions and third party failure make rebittances problematic and pose fundamental questions regarding whether they will continue to exist in the long term. The risks also raise concerns over what protections are currently available for rebittance users under New Zealand law. The next Part considers New Zealand's current regulation and concludes that a licensing system, operated through the "prescribed

80 Parsons, above n 6.

81 He and others, above n 64, at 29.

82 At 29.

83 He and others, above n 64. See also Murphy, Murphy and Seitzinger, above n 47.

84 Murphy, Murphy and Seitzinger, above n 47, at 8.

85 He and others, above n 64, at 28-29. 
intermediary services" mechanism that currently exists, could be an effective mechanism for covering these risks.

\section{CURRENT REGULATION}

There is no legislation or regulation in New Zealand which deals specifically with cryptocurrencies. This article suggests that analysis for how Bitcoin is regulated in New Zealand should come under the wider existing umbrella of financial markets regulation. The relevant legislation for this discussion is the Financial Markets Conduct Act 2013 (FMCA) and the Financial Service Providers (Registration and Dispute Resolution) Act 2008 (FSPA). In general terms, financial markets law seeks to "promote innovation and flexibility in the financial markets", 86 but this is balanced against ensuring adequate protections are in place so as to promote fairness, efficiency and transparency in financial markets. ${ }^{87}$

\section{A Legal Classifications: is Bitcoin a Currency or an Asset?}

Currently, there is no defined legal classification of Bitcoin in New Zealand. It is possible to conceptualise Bitcoin as either a currency or an asset. ${ }^{88}$ As there is no official New Zealand source material considering this topic, it is useful to consult international materials. The conclusion reached is that while Bitcoin can resemble commodity assets such as gold, it should be considered a currency.

The common law has not formulated a precise definition of currency. However, currency is generally regarded as having three main economic functions: a medium of exchange, a unit of account and a store of value. ${ }^{89}$ In its 2014 report on virtual currencies, the Financial Action Task Force (FATF), an intergovernmental body, defined digital currency as: ${ }^{90}$

... a digital representation of value that can be digitally traded and functions as (1) a medium of exchange;

and/or (2) a unit of account; and/or (3) a store of value, but does not have legal tender status ... in any

jurisdiction. It is not issued nor guaranteed by any jurisdiction, and fulfils the above functions only by

agreement within the community of users of the virtual currency. Virtual currency is distinguished from

fiat currency ... which is the coin and paper money of a country that is designated as its legal tender ...

Satoshi Nakamoto's white paper described Bitcoin as a "peer-to-peer ... electronic cash [system which] allow[s] online payments to be sent directly from one party to another without going through

86 Financial Markets Conduct Act 2013 [FMCA], s 4(d).

87 FMCA, ss 3(b) and 4(b).

88 Dirk Baur, KiHoon Hong and Adrian Lee "Bitcoin: Currency or Investment?" (7 February 2015) Social Science Research Network <www.ssrn.com>.

89 At 2; and Frederick Mann The Legal Aspect of Money (Oxford University Press, Oxford, 1938) at 7.

90 Financial Action Task Force Virtual Currencies: Key Definitions and Potential AML/CFT Risks (June 2014) at 4 (footnotes omitted). 
a financial institution". ${ }^{91}$ This suggests Bitcoin should be a digital currency, as Bitcoin's peer-to-peer network means it has a medium of exchange and Bitcoin is denominated in its own unit of account. ${ }^{92}$ However, Bitcoin is distinct from fiat currency as, where fiat currency is not truly scarce but issued by a nationalised central bank to control monetary policy, Bitcoin is intentionally scarce and nonnational in nature. This makes it more similar to commodity assets such as gold. On the other hand, there is an important similarity between fiat currency and Bitcoin in that they both lack intrinsic value and carry counter-party risk. ${ }^{93}$

The most contentious matter is whether Bitcoin acts as a store of value. ${ }^{94}$ The ability for a currency to store value depends on the confidence of users to be able to use it as payment for goods or services which "have a value in use or consumption". 95 Stability is perhaps the most important characteristic for determining the confidence of users of any currency as without stability people will not have confidence in a currency to retain its value. This arguably shows Bitcoin's weakness as a store of value and has led economists to proclaim that Bitcoin is an asset and not a currency. ${ }^{96}$ Yet, one can argue the volatility of Bitcoin applies more to the practical efficacy of holding Bitcoin rather than whether it can act as a store of value at all. Bitcoin lacks stable purchasing power, but that does not preclude an ability to store value. Currency derives its value in terms of the number of monetary units of account in existence and the market demand for that unit of account. Bitcoin functions in the same way, but as noted above the supply is fixed by the protocol governing its operation. ${ }^{97}$ As such, Bitcoin is capable of storing value in the exact same way as traditional currency, but it is more exposed to market forces.

The final objection to Bitcoin being a currency is the fact it is not used as payment in the sale of goods or services transactions by many people. ${ }^{98}$ The modern perception of currency typically requires it to be generally acceptable in the state where it circulates. ${ }^{99}$ As Bitcoin does not come from

91 Nakomoto, above n 35, at 1.

92 Baur, Hong and Lee, above n 88, at 2.

93 At 3 .

94 Lily Katz "Bitcoin Acceptance Among Retailers is Low and Getting Lower" (13 July 2017) Bloomberg <www.bloomberg.com>.

95 David Fox "Cyber-Currencies in Private Law" in Shelley Griffiths, Mark Henaghan and MB Rodriguez Ferrere (eds) The Search for Certainty: Essays in Honour of John Smillie (Thomson Reuters, Wellington, 2016) 129 at 136.

96 Jeffrey Dorfman "Bitcoin is an Asset, Not a Currency" (17 May 2017) Forbes (online ed, New York, 17 May 2017).

97 Fox, above n 95, at 130.

98 See Dorfman, above n 96; Fox, above n 95; and Katz, above n 94.

99 Fox, above n 95, at 131. 
a particular state, this becomes more complex. The question of whether something is a currency is therefore one of degree. Bitcoin can be used to book holidays, ${ }^{100}$ buy furniture, ${ }^{101}$ or make retail purchases on Amazon. ${ }^{102}$ Jurisdictions such as Japan have passed laws to recognise Bitcoin as a legal payment method. ${ }^{103}$ Additionally, Bitcoin has been considered as money by a United States court. ${ }^{104}$ There is therefore strong evidence for the suggestion that Bitcoin is accepted widely enough on a global scale and should be considered a currency. This does not mean it is legal tender in New Zealand, but comparable as something akin to foreign currency. ${ }^{105}$

\section{B Financial Product Regulation}

At its core, the FMCA imposes significant compulsory disclosure obligations on issuers of financial products and regulates the dealing of financial products and services. Additionally, the FMCA requires the licensing of particular financial service providers. There are potential criminal and civil penalties for failing to meet obligations under the Act. ${ }^{106}$ Under the FMCA, there are four classes of regulated financial products: debt securities; equity securities; managed investment products; and derivatives. ${ }^{107}$ For a product to be regulated under the FMCA, it must first come within one of these classes, as defined in the Act, or be designated as a financial product under one of these classes by the Financial Markets Authority (FMA) using its designation power. ${ }^{108}$

Cryptocurrencies do not fit neatly within any of the four classes of financial products, as defined in the FMCA. For example, Bitcoin cannot be described as an equity or debt security and does not come within the definition of a derivative. The closest class that Bitcoin could be compared to is a managed investment product, though the analogy is strenuous. Managed investment products are interests in a managed investment scheme as defined under s 9(1) of the FMCA. However, there is no managed investment scheme in existence when acquiring Bitcoin. Wallets are generally non-

100 Jamie Redman "The Many Ways You Can Book Your Travel Using Bitcoin" (15 February 2017) Bitcoin $<$ https://news.bitcoin.com>.

101 Overstock "Bitcoin on Overstock.com" <www.overstock.com>.

102 Antonio Madeira "2.3 Billion People Can Now Use Bitcoin on Amazon" (24 January 2017) Bitcoinist <www.bitcoinist.com>.

103 Arjun Kharpal "Bitcoin value rises over \$1 billion as Japan, Russia move to legitimize cryptocurrency" (12 April 2017) CNBC <www.cnbc.com>.

104 Securities Exchange Commission v Shavers 4:13-CV-416 (ED Tex 2013) [Shavers Case].

105 See also Angus Barclay "OIA Response Sent to a Journalist in January 2014" Reserve Bank of New Zealand <www.rbnz.govt.nz>

106 Part 8.

107 Section 7.

108 Part 9, sub-pt 3. 
custodial, meaning the user retains full control of their Bitcoin and there is no other party managing them on the user's behalf. ${ }^{109}$

Under s 562 of the FMCA, the FMA has the wide-ranging power to designate any security that would not normally be a financial product to be a financial product under any class of the FMA's choosing. ${ }^{110}$ In conjunction with its designation power, the FMA is also given the power to exempt any person or transaction, or class of such persons or transactions, from compliance with pts $2-7$ of the FMCA. ${ }^{111}$ Effectively, this means that the FMA could take a "best fit" approach to regulation and attempt to specifically address the issues retail users face when using Bitcoin. The FMA has not used its designation power to declare Bitcoin as a financial product. Therefore, Bitcoin is not currently subject to financial product regulation in New Zealand. The FMA could choose to designate Bitcoin as a financial product in the future. To do so would require meeting a two-stage test: first, the FMA must consider whether a security exists; ${ }^{112}$ second, the statutory requirements for exercising the designation power must be met. ${ }^{113}$ However, the conclusion reached below after discussion of the implications of designation is that there is little protection to be gained for retail users by the FMA designating Bitcoin as a financial product.

The FMCA defines a security as "an arrangement or a facility that has, or is intended to have, the effect of a person making an investment or managing a financial risk". ${ }^{114}$ This broadly-worded definition could include Bitcoin, as it has been widely used as a speculative investment. ${ }^{115}$ By statutory requirement, the FMA must exercise its designation powers in accordance with the purpose of the FMCA and in consultation with persons it considers would be significantly affected. Moreover, the FMA must have regard to the economic substance of the relevant security. ${ }^{116}$ The main purposes referred to in the FMCA are: "to- (a) promote the confident and informed participation of businesses, investors, and consumers in the financial markets; and (b) promote and facilitate the development of fair, efficient, and transparent financial markets". ${ }^{117}$ In evaluating whether regulating Bitcoin under the FMCA would achieve these purposes, it is prudent to consider what obligations and protections

109 See Abra "Where is the money held?" <https://abra.zendesk.com>.

110 Section 562.

111 Section 556

112 Section 6(1) definition of "security".

113 Section 562.

114 Section 6(1) definition of "security", para (a).

115 Baur, Hong and Lee, above n 88, at 2.

116 Section 563(1).

117 Section 3. 
might flow from designating Bitcoin as a financial product. This requires consideration of the Fair Dealing Rules (under pt 2) and the disclosure requirements (under pt 3).

\section{Fair Dealing Rules}

The Fair Dealing Rules set out compulsory behavioural standards for those operating in financial markets. ${ }^{118}$ Under the Fair Dealing Rules misleading or deceptive conduct and false, misleading or unsubstantiated representations are prohibited. ${ }^{119}$ The Fair Dealing Rules relate to both dealing in financial products (as above) and providing financial services. ${ }^{120}$ Accordingly, any person providing a "financial service" is subject to the Fair Dealing Rules, regardless of whether the service involves the issue or sale of a financial product.

"Financial service" means financial service as defined in s 5 of the FSPA. ${ }^{121}$ It also includes a "market service" but specifically excludes any service declared by regulations not to be a financial service for the purposes of the FMCA. ${ }^{122}$ Section 5 of the FSPA defines financial service as any one of a number of listed financial services. For the purposes of this article, the following are the most relevant: operating a money or value transfer service; ${ }^{123}$ managing means of payment; ${ }^{124}$ and changing foreign currency. ${ }^{125}$ This article argues Bitcoin should be treated as a currency and Bitcoin should be conceptualised as a money service. However, even if one adopts the view that Bitcoin is not a currency, it is difficult to say there is no value transfer service being provided during rebittances. Therefore, it is likely that rebittance providers would meet $s$ of the FSPA and be subject to the Fair Dealing Rules, regardless of whether or not Bitcoin was designated as a financial product. ${ }^{126}$

This regulation does not address the key risks that rebittance users face. Without breaching the Fair Dealing Rules, a rebittance provider could advertise that it does not charge a fee for its service to entice retail users. Yet, this would not inform users of the risks associated with the transaction.

118 Financial Markets Authority A Guide to the Financial Markets Conduct Act 2013 Reforms (November 2013) at 10 .

119 FMCA, ss 19-23.

120 Sections 19-21.

121 Section 6(1) definition of "financial service".

122 Financial Service Providers (Registration and Dispute Resolution) Act 2008 [FSPA], s 5.

123 Section $5(1)(f)$.

124 Section $5(1)(\mathrm{g})$.

125 Section $5(1)(j)$.

126 The FMA has recently confirmed that it classifies cryptocurrencies as coming within "operating a money or value transfer service": Financial Markets Authority "Cryptocurrency Services" <www.fma.govt.nz>. 
Further, as the Fair Dealing Rules are a general protection mechanism, they do little to protect users from third-party failure and are not helpful in signaling reliable rebittance providers to users.

\section{Disclosure obligations}

Part 3 of the FMCA places arduous disclosure obligations on persons making a regulated offer for financial products by requiring the issuer to create a Product Disclosure Statement (PDS) for the offer and lodge it with the registrar. ${ }^{127}$ An offer is "regulated" if at least one investor requires disclosure under pt 3. ${ }^{128}$ A PDS provides information to assist non-experts in their decision of whether to acquire a financial product. ${ }^{129}$ There are many issues with trying to apply these disclosure obligations to rebittances. The foremost is that Bitcoin has no issuer. Bitcoin are not issued by any entity, instead they are created automatically by the blockchain as a reward for miners when they successfully validate new blocks. ${ }^{130}$ Thus, Bitcoin cannot fit within these disclosure provisions. As there is no issuer, there is no one to take responsibility for creating a PDS. Rebittance providers are acting in an intermediary capacity in this regard.

Due to the fact rebittances providers likely already come under the Fair Dealing Rules for the provision of a financial service and there is no issuer for Bitcoin to enforce a disclosure obligation against, use of the designation power by the FMA to make Bitcoin a financial product would seemingly do little for any of the FMCA's purposes listed above. Further, designation would do little to address the risks, identified earlier, that retail users face. The only added benefit is that the FMA could clarify to the market exactly what it expects rebittance providers to comply with. As such, this article takes the view that Bitcoin should not be designated as a financial product.

\section{Licensing and Registration}

\section{Financial Service Providers Registration}

The FSPA is a light registration regime for all financial service providers based in New Zealand. As aforementioned, rebittance providers meet the definition of providing a financial service under s 5 of the FSPA. This requires New Zealand based rebittance providers to publicly register under the FSPA and to be a member of a dispute resolution scheme if they have retail clients. ${ }^{131}$ Under s $11(2)$ of the FPSA, it is an offence to provide financial services or hold out that financial services are provided without being registered. ${ }^{132}$ The FPSA does not place a large compliance burden on

127 Section 48.

128 Section 41.

129 Section 49.

130 The Economist, above n 51.

131 Section 3.

132 Section 11(2). 
cryptocurrency service providers. It requires the provision of basic information about their business to the registrar and, additionally, it provides an avenue for redress to consumers should a dispute arise through an applicable dispute resolution scheme. ${ }^{133}$

\section{Financial Markets Service Licence}

Part 6 of the FMCA requires providers of certain financial markets services to operate under a market services licence. ${ }^{134}$ This is limited to specified types of investment management schemes and derivatives issuers. ${ }^{135}$ Part 6 also allows for certain "prescribed intermediary services" to be licensed. ${ }^{136}$ This licensing regime is intended to be "risk-based, flexible and relatively 'light' by international standards" to ensure there are no undue barriers to entry or competition. ${ }^{137}$ This is achieved through leaving much of the detail to regulations. Regulations are made by an Order in Council of the Governor-General on recommendation of the Minister in consultation with the FMA. ${ }^{138}$ Currently, under the Financial Markets Conduct Regulations 2014 (FMC Regulations), only peer-to-peer lending and crowdfunding have been named as prescribed intermediary services. ${ }^{139}$ Thus, for rebittance providers to come within pt 6 of the FMCA, new regulations would need to be made. This has the benefit of allowing a bespoke approach to be taken for cryptocurrencies, particularly in relation to the obligations placed on licensed intermediaries that provide this type of service.

Under a market services licence, all licensees are subject to a general reporting requirement when certain significant events occur, such as: when it becomes likely the licensee will be subject to an insolvency event, there is a change in key staff, or relevant legal proceedings are issued against the licensee or its key staff. ${ }^{140}$ Additionally, the FMA may require the licensee to periodically report to the FMA concerning the nature, scale and operation of the service, including statistical information about transactions. ${ }^{141}$ Crowdfunding and peer-to-peer lending providers, as prescribed intermediary

133 FSPA, ss 15 and 48; and Companies Office "Dispute Resolution Schemes" <www.companiesoffice.govt.nz>.

134 Section 386.

135 Section 388

136 Section 390(1).

137 Office of the Minister of Commerce Financial Markets Conduct Regulations Article 4 - Licensing regimes (Cabinet Business Committee, September 2013) at 21.

138 FMCA, s 543.

139 See Financial Markets Conduct Regulations 2014 [FMC Regulations], reg 184.

140 Regulation 191.

141 Regulation 199. 
services, are also subject to additional disclosure obligations to investors. ${ }^{142}$ This includes providing retail investors with a service disclosure statement (SDS) to assist them in deciding whether or not to proceed with the service. ${ }^{143}$ The disclosures in the SDS relate to the service being provided by an intermediary, not an issuer. For crowdfunding specifically, the SDS must also display a prominent warning alerting retail investors to the general risks of crowdfunding and obtain confirmation from the investor that they have seen the warning and understand the risks. ${ }^{144}$ These obligations must be met every time before the retail investor enters into an agreement with the service provider. Breach of these conditions can give rise to civil and criminal penalties for the service provider. ${ }^{145}$ Thus, the disclosure onus is on the service provider, not the issuer as under pt 3 disclosure obligations.

If cryptocurrency service businesses were named as prescribed intermediary services and made subject to bespoke regulations which placed similar disclosure obligations and penalties to crowdfunding in place, this would directly address some of the key risks for rebittance users, such as the information asymmetries users are exposed to. It would also ensure users are aware of the price volatility risk and lack of intrinsic value. Additionally, the FMA could require rebittance providers to report periodically on their operations in New Zealand, such as their levels of activity and number of complaints received. This would allow the FMA to take a risk-based approach to supervision and monitor if further action is required. The general requirements for a pt 6 licence would help foster trust and confidence in licensed rebittance providers, due to the penalties that can be applied if the service providers do not comply with the terms of their licence. Bespoke regulations would also create market certainty over exactly what regulation rebittance providers are expected to comply with.

\section{Fair Trading}

Misleading or deceptive conduct in trade generally could come under the Fair Trading Act 1986 (FTA). The FMA and the Commerce Commission have a memorandum of understanding under which the Commission requires the FMA's consent to commence proceedings relating to a financial product or service. ${ }^{146}$ One significant difference between the Fair Dealing Rules and the FTA is that under the FTA the Commission has jurisdiction to bring a criminal case where there is "conduct that is liable to mislead the public as to the nature, characteristics, suitability for a purpose, or quantity of services". ${ }^{147}$ The requirement that the public must be misled necessitates there is the potential for

142 FMCA, pt 6, sub-pt 4; and FMC Regulations, regs 213-229.

143 FMCA, s 425. A user of a rebittance service could be considered an investor under the FMCA as the definition includes a person who receives a financial service: see FMCA, s 6.

144 FMC Regulations, reg 197.

145 FMCA, ss 421 and 429.

146 Financial Markets Authority and Commerce Commission "Memorandum of Understanding between Financial Markets Authority and Commerce Commission" (31 March 2014) <www.fma.govt.nz> at [4]

147 Fair Trading Act 1986 [FTA], s 11. 
misleading information to be publically disseminated, beyond just one person. ${ }^{148}$ On conviction, the fines imposed are limited to $\$ 200,000$ for an individual and $\$ 600,000$ for a body corporate. ${ }^{149}$ Under the Fair Dealing Rules, the FMA can bring a civil action for pecuniary penalties. ${ }^{150}$ The maximum penalty is the greatest of: the consideration of the transaction that breached the rules; three times the amount of the gain made or loss avoided; and \$1 million for an individual or \$5 million in any other case. ${ }^{151}$ Under both the Fair Dealing Rules and the FTA, an individual user could seek compensation for any loss caused by a rebittance provider's misleading or deceptive conduct. ${ }^{152}$ However, as with the Fair Dealing Rules discussed above, this offers little protection to the risks rebittance users are exposed to.

\section{E Issues Relating to Offshore Providers}

There are currently no New Zealand based rebittance providers. ${ }^{153}$ However, globally, the number of rebittance providers is growing. ${ }^{154}$ As transactions are entirely electronic, New Zealand based users can use the services of offshore providers. Jurisdictionally, the FMCA and FTA generally apply to conduct by a person outside of New Zealand if they are supplying services to persons in New Zealand. ${ }^{155}$ Under the FSPA, only persons who are resident or have a place of business in New Zealand must register, unless they are required to be registered by another enactment. ${ }^{156}$

There are enforcement difficulties against persons based overseas. It is easy to envisage a scenario where a retail user is misled into a transaction with an offshore rebittance provider with the promise of no fees and no risk, only to lose money as they were not aware of the substantial risks involved. While there may be a good cause of action under the Fair Dealing Rules, this will not help the user if the overseas person does not respond to the claim or disappears with the user's money. Issues pertaining to international enforcement are not new to e-commerce and cross-border payments, and are dependent on good cooperation between international regulators. ${ }^{157}$

148 Laws of New Zealand Consumer Protection (online ed) at [58].

149 FTA, s 40.

150 FMCA, s 489.

151 Section 490(1).

152 FTA s 43; and FMCA, s 494.

153 There are some New Zealand based cryptocurrency exchanges and some businesses which have issued their own cryptocurrency in an ICO: see Cryptopia <www.cryptopia.co.nz>.

154 Parsons, above n 6, at 12

155 FMCA, ss 33, 47, 239, 387 and 573; and FTA, s 3.

156 Section 8 A.

157 See Julia Hörnle Cross-border Internet Dispute Resolution (Cambridge University Press, Cambridge, 2009); and Shino Uenuma "Consumer Protection in Cross-Border E-Commerce Markets" in Takashi Kubota (ed) 
Yet, licensing and registration can be an effective mechanism to signal reputable financial services to users. A major issue is that overseas based cryptocurrency service providers which do not have a place of business in New Zealand are not required to be registered in New Zealand. For example, in June 2016, the FMA released a warning about IGOT, an Australian based Bitcoin exchange and rebittance provider, for failure to repay client funds. ${ }^{158}$ While the FMA notice did not acknowledge that IGOT dealt with Bitcoin, it did specify that IGOT was not required to be registered to provide financial services in New Zealand. If registration was required, rebittance users could identify providers which are able to provide financial services to persons in New Zealand. Under the FSPA, any person who is required to be a licensed provider under another statute is also required to be registered under the FSPA, regardless of whether they are based overseas. ${ }^{159}$ As discussed in Part VI, this article proposes that all rebittance providers offering services to persons in New Zealand be subject to licensing requirements which would address the issue of offshore providers.

\section{F Approach in Other Jurisdictions}

Currently, the FMA has taken a "light touch" approach toward cryptocurrency regulation. The FMA has published explanatory guidance on cryptocurrencies, initial coin offerings (ICOs), and cryptocurrency services. ${ }^{160}$ The FMA has confirmed that there is some protection to users available under existing financial markets law, preventing misleading conduct and requiring registration of New Zealand based cryptocurrency service providers. However, these measures serve as little better than a warning to users. They do little to address the risks users face when making rebittances and do not address the practical challenges brought by the borderless nature of cryptocurrencies. Before making recommendations on how New Zealand should regulate cryptocurrency services, such as rebittances, it is useful to present some approaches taken in other jurisdictions.

\section{United States}

United States regulators have been more active in issuing guidance relating to Bitcoin than their New Zealand counterparts. This is unsurprising given the relative size of the markets and levels of activity. The Securities Exchange Commission (SEC) has published warning advisories for consumers relating to the risk of scams using cryptocurrencies over the Internet. ${ }^{161}$ The SEC has also brought

Cyberlaw for Global E-Business: Finance, Payment, and Dispute Resolution (Information Science Reference, New York, 2008) 210.

158 Financial Markets Authority "A-Z List of all FMA Warnings" <https://fma.govt.nz>.

159 Section 8 A.

160 Financial Markets Authority "FMA Commentary on ICOs and Cryptocurrencies" (press release, 25 October 2017).

161 See United States Securities and Exchange Commission "Investor Alert: Bitcoin and Other Virtual CurrencyRelated Investments" (press release, 7 May 2014). 
successful prosecutions relating to investments purchased with Bitcoins, ${ }^{162}$ and for investing in Bitcoin. ${ }^{163}$ In the latter case, a federal court held that Bitcoin was a security, thus subject to federal securities law. ${ }^{164}$ A complaint has also successfully been brought under the Federal Trade Commission Act, which prohibits "unfair or deceptive acts or practices in or affecting commerce", ${ }^{65}$ where a business misled consumers who paid for Bitcoin mining machines and services the company sold over the Internet. ${ }^{166}$ In addition, the Commodity Futures Trading Commission has declared Bitcoin a commodity for its purposes so that it has jurisdiction to bring charges relating to Bitcoin. ${ }^{167}$ At the state level, the New York State Department of Financial Services requires all Bitcoin businesses operating in New York State to be licensed. ${ }^{168}$ This makes licensed businesses subject to minimum capital adequacy requirements along with other obligations. ${ }^{169}$ Both California and Connecticut are in the process of implementing similar arrangements. ${ }^{170}$ As Bitcoin is subject to these various regulations, Bitcoin users are effectively protected to a similar level as if they were buying any other security in the United States.

\section{Australia}

Like New Zealand, Australia has not taken substantive steps in regulating Bitcoin yet. ${ }^{171}$ The purchase of Bitcoin with fiat currency is not regulated as a money exchange by the Australian Securities and Investments Commission (ASIC). ${ }^{172}$ As such, the regulatory framework for foreign

162 See United States Securities and Exchange Commission "SEC Charges Bitcoin Entrepreneur with Offering Unregistered Securities" (press release, 3 June 2014).

163 Shavers Case, above n 104.

164 Shavers Case, above n 104

165 Federal Trade Commission Act 15 USC $\$ 45$.

166 Federal Trade Commission v BF Labs, Inc 4:14-CV-815-BCW (WD MO 2014).

167 United States Commodity Futures Trading Commission "CFTC Orders Bitcoin Options Trading Platform Operator and its CEO to Cease Illegally Offering Bitcoin Options and to Cease Operating a Facility for Trading or Processing of Swaps without Registering" (press release, 17 September 2015). See also Commodity Futures Trading Commission "Order Instituting Proceedings Pursuant to Sections 6(c) and 6(d) of the Commodity Exchange Act, Making Findings and Imposing Remedial Sanctions" (CFTC Docket No 15-29, 17 September 2015).

168 New York Codes, Rules and Regulations, title 23, ch I, pt 200.

169 Murphy, Murphy and Seitzinger, above n 47, at 14-15.

170 At 16.

171 See Parsons, above n 6.

172 See Senate Standing Committees on Economics Digital Currency-game changer or bit player (August 2015) at $[5.14]$ 
currency exchanges does not apply to rebittance providers or Bitcoin exchanges. ${ }^{173}$ Thus, users may lack some protection in this regard. Additionally, ASIC does not consider Bitcoin to be a "financial product" under the Corporations Act 2001 or the Australian Securities and Investments Commission Act 2001. ${ }^{174}$ This means rebittance providers are not providing financial services in the provision of their service. ${ }^{175}$ The exception to this is where Bitcoin is one of several financial products a financial institution offers to its customers. ${ }^{176}$ In such a case Bitcoin would be considered a financial product and regulatory protections would apply. Where the Bitcoin exchange or rebittance provider is determined to be a "corporation" under the Competition and Consumer Act 2010, then consumers may have access to statutory remedies under Australian Consumer Law if there is misleading or deceptive conduct in the provision of services. ${ }^{177}$ ASIC has also issued advisory warnings for consumers about the risks of buying Bitcoin. ${ }^{178}$

\section{RECOMMENDATIONS}

The comparative analysis shows that other jurisdictions have been more proactive than New Zealand in clarifying the legal treatment of Bitcoin, issuing risk warnings to retail users, and in some cases expanding regulatory frameworks to accommodate the unique regulatory challenges Bitcoin presents. The recommendations presented in this Part disagree with the Australian approach and argue New Zealand regulation should provide more protection for retail users of cryptocurrencies.

This can be achieved by requiring cryptocurrency service providers who supply financial services to persons in New Zealand, wherever based, to be subject to licensing requirements. The best way to achieve this is to make exchange of cryptocurrency for fiat currency a "prescribed intermediary service" under pt 6 of the FMCA and subject to a market services licence. As discussed above, any rebittance provider who wished to provide services to users based in New Zealand would need to register for a licence and disclose such registration to users. Disclosure obligations would be imposed to ensure unsophisticated retail users of rebittances are properly made aware of the risks of the transactions they are making. In addition to the general reporting requirements of a market services licence, the FMA should require regulatory reports from rebittance providers on their operations in

173 Parsons, above n 6, at 22-23. See Senate Standing Committees on Economics, above n 172, at [5.12]-[5.23].

174 Corporations Act 2001 (Cth), s 763A; and Australian Securities and Investments Commission Act 2001 (Cth), s 12BAA. See also Senate Standing Committees on Economics, above n 172, at [5.12]-[5.23].

175 Senate Standing Committees on Economics, above n 172, at [2.16]; and Australian Securities and Investments Commission Senate Inquiry into Digital Currency - Submission by the Australian Securities and Investments Commission (Submission 44, December 2014) at 11.

176 See Senate Standing Committees on Economics, above n 172, at [5.12]-[5.23].

177 Competition and Consumer Act 2010 (Cth), sch 2 s 18. See also Parsons, above n 6, at 23-24.

178 Australian Securities \& Investments Commission "Cryptocurrencies" (11 April 2018) <www.money smart.gov.au>. 
New Zealand. This would help identify any providers that receive large numbers of complaints or are acting fraudulently. The FMA should have the power to revoke a provider's licence in such a case. Additionally, this solution would overcome the issue of overseas providers; pt 6 of the FMCA applies to prescribed intermediary services received by an investor in New Zealand, regardless of where the provider is resident, incorporated or carrying on their business. ${ }^{179}$

This article suggests these disclosure obligations are proportional to the heightened risks retail users face when using rebittances as opposed to traditional remittances. This bespoke approach allows the issues raised by Bitcoin, namely users not understanding the risks they are taking, to be addressed. Unfortunately, the FMA has recently released guidance to the effect that it considers creating a new prescribed intermediary service for cryptocurrency exchange services would take too long and the risks presented could be regulated in other ways. ${ }^{180}$ However, the FMA's alternative approach of having information available on their website does not go far enough, as many retail users may engage with cryptocurrency services without properly understanding the risks and only see the FMA's materials after having an issue with their cryptocurrency service provider. Putting the onus on cryptocurrency service providers to inform their users of the risks would provide for better protection and more informed use of cryptocurrency services, including rebittances.

The suggested approach does not directly protect users against the risk of third-party failure, yet stricter obligations would become burdensome for cryptocurrency service providers. However, the recommendations offer some protection against fraudulent providers. If the above recommendations are adopted, it could have positive outcomes for the cryptocurrency service industry; users would have avenues of dispute resolution open to them which would promote trust and confidence in dealing with a licensed provider. The obligations suggested above are not overly onerous. Yet, they would help break down some of the misgivings users have towards Bitcoin and other cryptocurrencies due to involvement in illicit uses. This could see the Bitcoin market grow, which as Bitcoin matures, could result in a more stable currency leading to less risk for rebittance users. However, it is too early to suggest whether this will result or not.

\section{CONCLUSION}

This article illustrates one example of the many regulatory issues that have arisen through the emergence of cryptocurrency. Globally, there is a need for cheaper remittances, especially for developing countries where the cost of sending remittances is often highest. A large proportion of remittances are sent to developing countries and remittances play a key role in aiding social development and innovation. Bitcoin has been heralded as an opportunity to reduce fees involved with remittances through its use of blockchain technology, yet it has flaws which make it problematic for

179 Section 387.

180 See Financial Markets Authority, above n 160; and "FMA Gives Heads-up on Crypto-coin Regulation" (29 October 2017) Investment News <http://investmentnews.co.nz>. 
use in remittance markets. There are other cryptocurrencies which overcome some of these flaws and may be more appropriate for use with remittances. However, to unsophisticated retail users, there are many risks involved with using cryptocurrencies for remittances. Under the current framework, there is modest protection at best for retail users if the cryptocurrency service provider is based in New Zealand; there is even less if the provider is based overseas. While New Zealand regulators have published some guidance on the risks of cryptocurrencies, they are a step behind their international counterparts in terms of the amount of guidance provided to the public about the risks posed by Bitcoin and other cryptocurrencies.

New Zealand has a flexible regulatory framework and offers a possible solution: namely regulating cryptocurrency services, such as rebittances, as a "prescribed intermediary service" under pt 6 of the FMCA. This would provide protection by way of disclosure to unsophisticated retail users without stifling the innovation behind the technology with cumbersome obligations. New Zealand is equipped with the tools to help foster the growth of an industry which could provide substantial benefits to both individuals and society; what is required is for regulators and the Government to commit to using those tools in aid of innovation. 
